\title{
Rancang Bangun Simulator Kincir Pembangkit Listrik Floating Hydro
}

\author{
Dian Prabowo ${ }^{1}$ Pujono $^{2}$ \\ 1,2 Jurusan Teknik Mesin, Politeknik Negeri Cilacap \\ Email : 1dianprabow087@gmail.com, ${ }^{2}$ poejono07@gmail.com
}

\begin{abstract}
ABSTRAK
Konsumsi energi di Indonesia semakin tahun semakin meningkat, pemenuhan dari energi yang dibutuhkan harus bisa diatasi. Energi adalah merupakan hal yang sangat dibutuhkan oleh siapapun dari manusia maupun hewan agar bisa melakukan sesuatu atau usaha. Energi ini juga bersifat abstrak, keberadaannya dapat dirasakan namun sulit untuk dibuktikan. Kebutuhan listrik masyarakat saat ini merupakan kebutuhan pokok. Pemakaian listrik hampir 24 jam nonstop. Untuk mengatasi kebutuhan listrik yang semakin meningkat perlu adanya pemanfaatan sumber daya alam yang dapat dijadikan sebagai sumber energi baru. Alat simulator pembangkit listrik floating hydro adalah pembangkit listrik tenaga air yang memanfaatkan aliran air dari pompa untuk menggerakan kincir air, alat yang dirancang untuk memudahkan mahasiswa belajar teknik listrik dasar dan mekanika fluida. Tujuan perancangan ini, merancang dan membuat pembangkit listrik Floating hydro serta menguji alat tersebut. Metode perancangan menggunakan pendekatan metode VDI 2222, yaitu meliputi merencana, mengkonsep, merancang, penyelesaian. Hasil dari perancanganya itu sesuai metode yang digunakan yaitu berupa desain simulator kincir air pembangkit listrik. Estimasi waktu proses produksi pembuatan alat simulator floating hydro untuk pemotongan 3,9 jam; proses gurdi 3,08 jam; proses bubut 1,3 jam; proses perakitan 1,58 jam; proses finishing $2,75 \mathrm{jam}=1,2$ hari $(1$ hari $=8$ jam $)$. Total biaya pembuatan mesin sebesar Rp 2.605.740,00. Uji hasil pulley penggerak menghasilkan 65,4 rpm dan pulley yang digerakan menghasilkan 304 rpm dan mendapatkan hasil output sebesar 12,3 volt.
\end{abstract}

Kata Kunci: Energi,Simulator, floating hydro, listrik, perancangan, produksi.

\begin{abstract}
Energy consumption in Indonesia is increasing every year, the fulfillment of the energy needed must be overcome. Energy is something that is really needed by anyone, from humans or animals to be able to do something or work. This energy is also abstract, its existence can be felt, but it is difficult to prove. Electricity needs of the community today are a basic need. Electricity usage is almost 24 hours nonstop. To cope with the increasing demand for electricity, it is necessary to utilize natural resources that can be used as new energy resources. The floating hydro power plant simulator is a hydroelectric power plant that utilizes the flow of water from a pump to drive a waterwheel, a device designed to make it easier for students to learn basic electrical engineering and fluid mechanics. The purpose of this design is to design and build a floating hydro power plant and test the tool. The design method used the VDI 2222 method approach, which includes planning, conceptualizing, designing, finishing. The results of the design were according to the method used, namely in the form of a waterwheel simulator design for power plants. The estimated production process time for the manufacture of a floating hydro simulator for cutting 3.9 hours; process of gurdi 3.08 hours; lathe process 1.3 hours; 1.58 hours assembly process; finishing process 2.75 hours $=1.2$ days $(1$ day $=8$ hours). The total cost of making the machine was Rp. 2.605,740.00. The driven pulley test results in 65.4 rpm and the driven pulley produced 304 rpm and the output was 12.3 volts.
\end{abstract}

Keywords: Energy, Simulator, floating hydro, electricity, design, production 


\section{Pendahuluan}

Konsumsi energi di Indonesia dari tahun 2000 sampai dengan 2004 terjadi lonjakan cukup signifikan dan mengalami peningkatan $5,2 \%$ pertahunnya dalam penggunaan energi, peningkatan tersebut melebihi peningkatan konsumsi energi pada tahuan 1995 sampai dengan 2000, dimana mencapai 2,9\% pertahunnya. Peningkatan tersebut maka dapat diperkirakan pasokan sumber listrik akan terus bertambah dimana mencapai 4,6\% pertahunnya, perkiraan penggunaan tersebut juga diprediksi sampai tahun 2030 ada penambahan tiga kali lipat pertahunnya [1]. Pada gambar 1 dibawah ini tertera kebutuhan dan produksi di Indonesia.

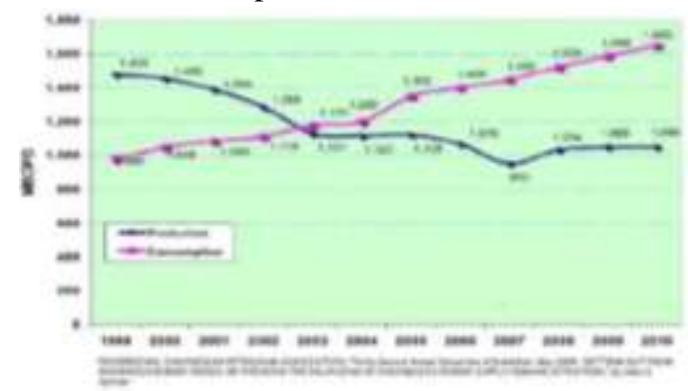

Gambar 1. Kebutuhan dan produksi energi di Indonesia tahun 1999 sampai dengan 2010

Energi adalah merupakan hal yang sangat dibutuhkan oleh siapapun dari manusia maupun hewan agar bisa melakukan sesuatu atau usaha. Energi ini juga bersifat abstrak keberadaannya dapat dirasakan namun sulit untuk dibuktikan [2]. Kemudian usaha juga dapat didefiniskan dengan energi yang disalurkan untuk membuat perubahan [3].

Fluida dikenal dengan suatu zat dapat berubah wujud sesuai dengan bentuk tempatnya atau wadahnya, perubahan tersebut diakibatkan gaya geser yang terjadi dalam proses tersebut. Fluida mempunyai dua jenis yaitu fluida gas dan fluida cair [4].

Simulator adalah suatu alat yang dapat digunakan sebagai media pembelajaran dimana desain dan bentuknya menyerupai aslinya sampai dengan fungisnyapun sama dengan aslinya. Simulator tersebut juga bisa untuk memperkenalkan kepada oranglain mengenai komponen, cara kerja dan fungsi dari suatu alat [5]. Dalam hal ini simulator yang digunakan adalah menggunakan air, dimana air tersebut digunakan sebagai sumber penghasil listrik. Semakin besar besar volume aliran air yang digunakan maka semakin besar juga energi listrik yang dihasilkan dari proses tersebut.

Floating hidro atau white resources adalah suatu sumber energi listrik yang memanfaatkan sumber daya alam yang ada. Di indonesia khususnya sumber daya alam air yang melimpah seperti sungai atau yang lainnya [6].
Floating hidro termasuk dalam energi potensial dimana memanfaatkan aliran air dari ketinggian, konsepnya semakin tinggi aliran maka semakin cepat pula air yang mengalir dan secara otomatis semakin besar pula energi potensialnya. Beberapa daerah yang kesulitan akan listrik maka dapat memanfaatkan aliran air sebagai sumber energi listriknya seperti digunakannya kincir air. Kemudian aliran air yang rendah bisa memanfaatkan kincir air jenis Floating hidro. Energi mekanik dari Floating hidro akan dipindahkan menjadi energi listrik yang prosesnya dibantu oleh generator.

\section{Tujuan}

Tujuan dari rancang bangun ini adalah:

a. Rancang bangun Simulator pembangkit listrik tenaga air berupa kincir air.

b. Melakukan pengujian alat simulator pembangkit listrik Floating Hydro.

\section{Tinjauan Pustaka}

Pembangkit Listrik Tenaga Mikro Hidro atau PLTH mempunyia potensi yang cukup baik dengan melihat kondisi geografis di Indonesia. PLTMH sendiri mempunyai prinsip kerja yaitu dengan memanfaatkan perbedaan ketinggian yang ada pada aliran suangi dan volume air yang masuk per detik. Aliran air yang mengalir ke penstock tersebut akan memutar sudu-sudu turbin kemudian putaran tersebut digunakan untuk menggerakan generator dan menghasilkan suatu listrik. Metode pengerjaan yang dilaksanakan adalah metode analisa (desk study analysis) dan metode survey dan observasi lapangan, penelitian dilakukan 4 lokasi yaitu Jombok, Waturejo, Ngantru 1, Ngantru 2 dimana 4 lokasi mempunyai debit air yang berbeda beda, hasil dari penelitian ini rata-rata energy terbangkitkan untuk 4 lokasi pengamatan sebesar $47.75 \mathrm{KW}$. Hasil tersebut bisa digunakan untuk memenuhi kebutuhan 47 rumah jika asumsi setiap rumah adalah $1 \mathrm{KW}$ [7].

Ainun Nidhar melakukan penelitian menggunakan kincir air tipe breast shot dengan variabel tetapnya adalah 6 sudu, 8 sudu dan 10 sudu sedangkan untuk variabel bebasnya setiap kincir sudutnya sudu bisa dirubah yaitu $0^{\circ}, 30^{\circ}$, dan $45^{\circ}$. Penelitian tersebut menghasilkan daya listrik 0,381 watt putaran 166,147 dan sudut sudu $45^{\circ}$ kemudian mendapatan efisiensi sebesar $48,962 \%$ pada sudu 8 dengan sudut sudu $45^{\circ}$ [8].

Penelitian menggunakan kincir air model breast shot di Universitas Queen menggunakan ketinggian 1,5 - 2,5 meter dengan diamter kincir sebesar 4 meter diperuntukan penjelasan prinsip kerja sampai dengan contoh perhitungannya. Pengujian tersebut menggunakan skal 1:4 yaitu memiliki diamter 1 meter dari data tersebut mendapatkan hasil tingkat efisiensi sebesar $78,5 \%$ pada arus yang luas dan efisiensi maksimalnya sampai dengan $87,3 \%$ [9]. 


\section{Metodologi Penelitian}

Prosedur rancang bangun merupakan langkah atau tahapan dalam membuat bagian komponen mesin floating hydro. Ada 2 prosedur yang terdapat pada prosedur rancang bangun yaitu prosedur perancangan dan prosedur produksi. Diagram alir dari proses rancang bangun mesin floating hydro.

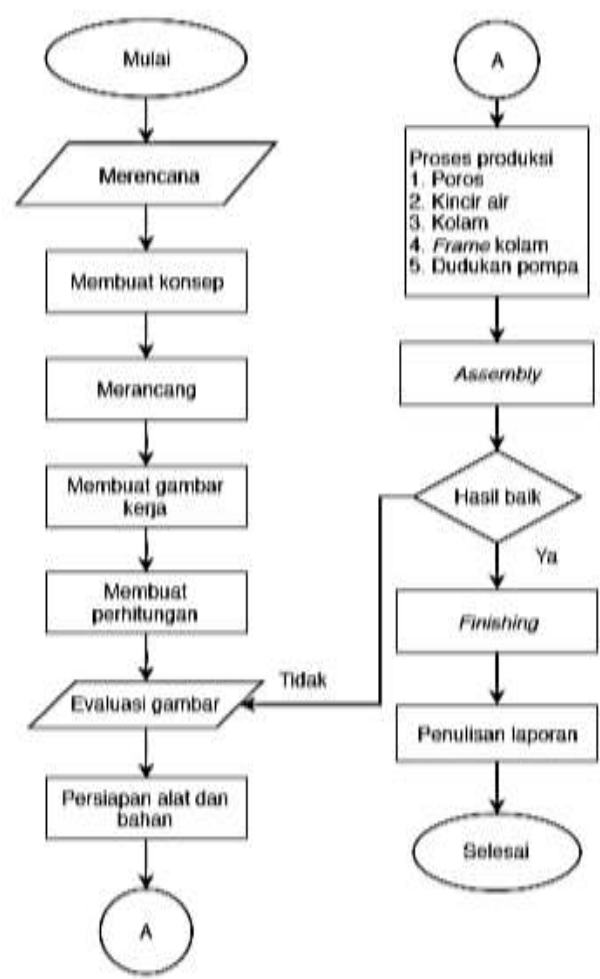

Gambar 1. Prosedur rancang bangun

\section{Hasil dan Pembahasan}

\subsection{Konsep}

Pada tahap konsep penulis menyusun segala kemungkinan yang dapat di gunakan pada table konsep. Konsep yang di pertimbangkan adalah untuk desain pada alat floating hydro. Berikut merupakan tabel konsep pertimbangan.

Tabel 1. Konsep Pertimbangan

\begin{tabular}{cccc}
\hline \multirow{2}{*}{ No } & Fungsi Bagian & \multicolumn{2}{c}{ Konsep } \\
\cline { 3 - 4 } 2 & Sistem Penggerak & Pompa air $100 \mathrm{~W}$ & Pompa air $30 \mathrm{~W}$ \\
3 & Jenis Kincir Air & Undeshot & \\
& & &
\end{tabular}

\subsection{Perhitungan pompa air}

a. Spesifikasi pompa air :

$\begin{array}{ll}\mathrm{Q}=0,00117 & \mathrm{~m}^{3} / \mathrm{s} \\ \mathrm{g}=10 & \mathrm{~m} / \mathrm{s}^{2} \\ \mathrm{D}=20 & \mathrm{~mm} \\ \mathrm{P}=100 & \mathrm{~W}\end{array}$

b. Dimensi lintasan air :
$\mathrm{p}=438 \mathrm{~mm}$
$1=50 \quad \mathrm{~mm}$
$\mathrm{t}=900 \mathrm{~mm}$

c. Menghitung kecepatan aliran air pompa

$$
\begin{aligned}
\mathrm{V}_{1} & =\mathrm{Q} / \mathrm{A} \\
& =\frac{0,00117}{0,000314} \\
& =3,72 \mathrm{~m} / \mathrm{s}
\end{aligned}
$$

d. Menghitung kecepatan air setelah melewati pipa $=A_{1} \times V_{1}=A_{2} \times V_{2}$

$$
=0,000314 \times 3,72=0,0219 \times \mathrm{V} 2
$$

$$
\begin{aligned}
\mathrm{V} 2 & =\frac{0,00117}{0,0219} \\
& =0,05 \mathrm{~m} / \mathrm{s}
\end{aligned}
$$

e. Menghitung tekanan air P2 menggunakan tekanan atsmosfir

$$
\begin{aligned}
1,01 \times 10^{5} \mathrm{~Pa} \\
\frac{P 1}{V 1}=\frac{P 2}{V 2} \\
\frac{P 1}{3,72}=\frac{1,01 \times 10^{5}}{0,05} \\
0,05 \mathrm{P} 1=9,797 \times 10^{5} \\
\mathrm{P} 1 \quad=\frac{3,75 \times 10^{5}}{0,05} \\
\mathrm{P} 1 \quad=75 \times 10^{5} \mathrm{~Pa}
\end{aligned}
$$

\subsection{Perhitungan kincir air brastshot}

a. Menghitung Jarak Antar Sudu.

$$
\begin{aligned}
\mathrm{t} & =\frac{D_{\text {in } X \pi}}{n_{\text {sd }}} \\
t & =\frac{500 \times 3,14}{20} \\
t & =78,5 \mathrm{~mm}
\end{aligned}
$$

b. Menghitung gaya fluida yang mengenai sudu.

$$
\begin{aligned}
\mathrm{F} & =\rho \times \mathrm{A} \times \mathrm{V}^{2} \\
& =1000 \times 0,0219 \times 0,05^{2} \\
& =0,05 \mathrm{~N}
\end{aligned}
$$

$$
\begin{aligned}
\mathrm{T} & =\mathrm{F} \times \mathrm{r} \\
& =0,05 \times 0,25 \\
& =0,0125 \mathrm{~N} . \mathrm{m}
\end{aligned}
$$

d. Menghitung kecepatan sudut

$$
\begin{aligned}
w & =\frac{2 \times \pi \times n}{60} \\
& =\frac{2 \times 3,14 \times 75}{60} \\
& =7,85 \mathrm{rad} / \mathrm{s}
\end{aligned}
$$


e. Menghitung daya kincir

$$
\begin{aligned}
P & =T \times W \\
& =0,0125 \times 7,85 \\
& =0,098 \text { watt }
\end{aligned}
$$

\subsection{Perhitungan Sistem Transmisi}

Daya kincir $\left(P_{k}\right)=0,098$ Watt), putaran $\left(n_{1}\right)=75$ dan $\frac{1}{2}$ diameter puli yang digerakan $(\mathrm{r})=0,0635 \mathrm{~m}$. Jadi untuk menghitung besarnya gaya tarikan sabuk-V dapat dihitung dengan rumus berikut ini :

$$
P_{k}=\text { T. } \omega
$$

Dimana :

$$
\begin{aligned}
& \omega=\frac{2 \cdot \pi \cdot n_{1}}{60} \\
& \omega=\frac{2 \cdot 3,14 \cdot 75}{60}=7,85 \mathrm{rad} / \mathrm{det}
\end{aligned}
$$

Maka :

$$
\begin{aligned}
& \mathrm{T}=\frac{\mathrm{Pk}}{\omega} \\
& \mathrm{T}=\frac{0,098}{7,85} \\
& \mathrm{~T}=0,0125 \text { N.m }
\end{aligned}
$$

Sehingga besarnya gaya tarik sabuk-V adalah sebagai berikut :

$$
\begin{aligned}
T & =\mathrm{F} \times \mathrm{r} \\
\mathrm{F} & =\frac{0,012 \mathrm{~N} \cdot \mathrm{m}}{0,0635 \mathrm{~m}} \\
\mathrm{~F} & =0,19 \mathrm{~N}
\end{aligned}
$$

\subsection{Perhitungan Elemen Mesin}

a. Diameter poros dapat diketahui dengan rumus sebagai berikut.

$$
\begin{aligned}
& d_{s} \geqq\left[\left(\frac{5,1}{\tau_{a}}\right) \sqrt{\left(K_{m} M\right)^{2}+\left(K_{t} T\right)^{2}}\right]^{1 / 3} \\
& d_{s} \geqq\left[\left(\frac{5,1}{6,7 \mathrm{Kg} / \mathrm{mm}^{2}}\right) \sqrt{(1,5 \times 1439)^{2}+(1 \times 15,58)^{2}}\right]^{1 / 3} \\
& d_{s} \geqq\left[0,76\left(\mathrm{Kg} / \mathrm{mm}^{2}\right) \sqrt{4659122+242,736}\right]^{1 / 3} \\
& d_{s} \geqq 11,50 \mathrm{~mm} \\
& d_{s} \approx 12 \mathrm{~mm}
\end{aligned}
$$

Jadi, diameter poros yang akan digunakan adalah $12 \mathrm{~mm}$.

b. Perhitungan umur bantalan

Perhitungan rating dasar untuk keandalan $90 \%$

$$
\begin{aligned}
& \mathrm{L} 10=\{\mathrm{C} / \mathrm{P}\} 3 \\
& \mathrm{~L} 10=\{1,74 / 0,0128\} 3 \\
& \mathrm{~L} 10=\llbracket 135,93 \rrbracket \wedge 3 \\
& \mathrm{~L} 10=2511989,59 \text { putaran }
\end{aligned}
$$

Perhitungan rating dasar untuk keandalan $90 \%$
$\mathrm{L} 10 \mathrm{~h}=\left[10^{\wedge} 6 /(60 \times \mathrm{n})\right] . \mathrm{L} 10$
$\mathrm{L} 10 \mathrm{~h}=[1000000 /(60 \times 75)], 2511989,59$
$\mathrm{L} 10 \mathrm{~h}=222,2.2511989,59$
$\mathrm{L} 10 \mathrm{~h}=558164086,90$ jam beroperasi

Dalam 1 hari, mesin bekerja selama 24 jam

$$
\begin{array}{ll}
\mathrm{n}=75 \mathrm{rpm} \times 60 \text { menit } & =4500 \mathrm{rph} \\
1 \text { hari bekerja }=4500 \times 24 & =112500 \mathrm{rph}
\end{array}
$$

Jadi umur bantalan dapat diketahui dengan perhitungan sebagai berikut :

$$
\begin{aligned}
& =558164086,90 / 112500 \\
& =4961,45 \text { hari } \\
& =13,78 \text { tahun }
\end{aligned}
$$

\subsection{Hasil Rancangan}

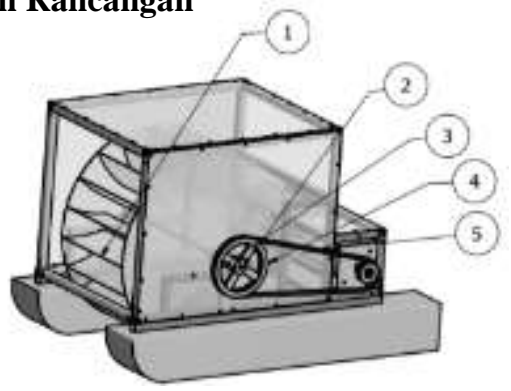

Gambar 2. Hasil Rancangan Flotyng hydro Keterangan :

1. Kincir air breastshot

2. Poros

3. Pillowbearing

4. Pulley

5. Sabuk

\subsection{Proses Produksi}

Proses produksi pembuatan alat floatyng hydro membutuhkan waktu 12,61 jam seperti terlihat pada Tabel 2. Estimasi waktu proses produksi, dimana proses produksi terdiri dari pemotongan dan bending, gurdi, bubut, perakitan dan proses finishing.

Tabel 2. Estimasi waktu proses produksi

\begin{tabular}{ccc}
\hline No & $\begin{array}{c}\text { Proses } \\
\text { Pengerjaan }\end{array}$ & $\begin{array}{c}\text { Waktu } \\
\text { Pengerjaan }\end{array}$ \\
\hline 1 & Pemotongan dan & 3,9 jam \\
& Bending & \\
2 & Gurdi & 3,08 jam \\
3 & Bubut & 1,3 jam \\
4 & Perakitan & 1,58 jam \\
5 & Finishing & 2,75 jam \\
Total Waktu Pengerjaan & $\mathbf{1 2 , 6 1 ~ j a m ~}$ \\
\hline
\end{tabular}

Selanjutnya dalam pembuatan alat simulator floating hydro menghabiskan biaya sampai 2,606.740,00

Setelah melakukan uji fungsi pada alat simulator floating hydro mendapatkan hasil bahwa semua komponen bisa berjalan sesuai dengan apa yang diharapkan. Seperti terluhat pada Tabel 3. Mengenai uji fungsi dibawah ini. 
Tabel 3. Uji Fungsi

\begin{tabular}{|c|c|c|c|c|}
\hline \multirow{2}{*}{ No } & \multirow{2}{*}{ Uraian } & \multicolumn{2}{|c|}{ Berfungsi } & \multirow{2}{*}{ Keterangan } \\
\hline & & Ya & Tidak & \\
\hline 1 & $\begin{array}{l}\text { Apakah kecepatan } \\
\text { pompa dapat } \\
\text { memutar kincir air? }\end{array}$ & $\sqrt{ }$ & & Berfungsi \\
\hline 2 & $\begin{array}{l}\text { Apakah kincir dapat } \\
\text { meneruskan daya ke } \\
\text { generator? }\end{array}$ & $\sqrt{ }$ & & $\begin{array}{c}\text { Bergerak } \\
\text { dengan Baik }\end{array}$ \\
\hline 3 & $\begin{array}{l}\text { Apakah sistem } \\
\text { transmisi dapat } \\
\text { bekerja? }\end{array}$ & $\sqrt{ }$ & & Berfungsi \\
\hline
\end{tabular}

Setelah melakukan tahapan uji fungsi pada komponen maka dilakukan pengujian hasil dalam pengujian hasil tersebut mendapatkan data bahwa putaran yang dihasilkan pulley penggerak yaitu 65,4 rpm sedangkan yang digerakan mendapatkan putaran 304,3 rpm dan output yang dihasilkan mendapatkan arus sebesar 12,3 volt. Seperti terlihat pada Tabel 5. mengenai uji hasil dibawah ini.

\begin{tabular}{lccc}
\multicolumn{4}{c}{ Tabel 5. Uji Hasil } \\
Uraian & $\begin{array}{c}\text { Pulley } \\
\text { penggerak } \\
(\mathbf{r p m})\end{array}$ & $\begin{array}{c}\text { Pulley yang } \\
\text { digerakan } \\
(\mathbf{r p m})\end{array}$ & $\begin{array}{c}\text { Output } \\
\text { (volt) }\end{array}$ \\
Putaran yang & 64,3 & 304,4 & 6,2 \\
dihasilkan & 64,3 & 228,2 & 8,7 \\
& 65,4 & 304,3 & 12,3
\end{tabular}

\section{Kesimpulan}

Setelah melakukan uji fungsi dan uji hasil mendaptkan kesimpulan yaitu perancangan simulator floating hydro melalui beberapa tahap yaitu melakukan perencanaan, membuat konsep, merancang dan melakukan penyelesaian.

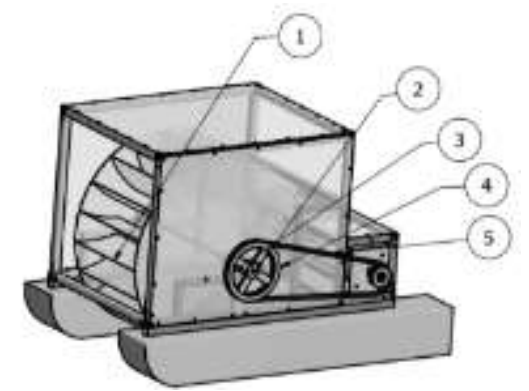

Gambar 3. Desain hasil Rancangan Flotyng hydro

Keterangan :

1. Kincir air breastshot

2. Poros

3. Pillowbearing

4. Pulley

5. Sabuk
Estimasi waktu proses produksi pembuatan alat simulator floating hydro untuk pemotongan 3,9 jam; proses gurdi 3,08 jam; proses bubut 1,3 jam; proses perakitan 1,58 jam; proses finishing 2,75 jam $=1,2$ hari (1 hari $=8$ jam $)$

Uji hasil pulley penggerak menghasilkan 65,4 rpm dan pulley yang digerakan menghasilkan $304 \mathrm{rpm}$ dan mendapatkan hasil output sebesar 12,3 volt.

\section{Daftar Pustaka}

[1] A. A. Larasakti, S. Himran, and A. Syamsul, "Pembuatan dan Pengujian Pembangkit Listrik Tenaga Mikrohidro Turbin Banki Daya 200 Watt," J. Mek., vol. 3, no. 1, pp. 245-253, 2012.

[2] N. Pudjanarsa Astu and Djati, Mesin Konversi Energi. Yogyakarta: Andi Offset, 2008.

[3] A. dan M. L. Alfatah, Bahas Tuntas 1001 Fisika SMP kelas VII, VIII, XI. Yogyakarta: Pustaka Widyatama, 2009.

[4] Djojodiharjo, Mekanika Fluida. Jakarta: Erlangga, 1982.

[5] M. D. Kardono, L. A. Delia, E. Sigitkurniawan, M. P. S. D. Hidro-oseanografi, and D. P. P. D. Hidro-oseanografi, PENCITRAAN BAWAH LAUT MENGGUNAKAN SENSOR WATERPROOF ULTRASONIC," J. HIDROPILAR, vol. 5, no. 2, pp. 79-88, 2019.

[6] M. Dafit Riandi, Kaidir, "PEMBANGKIT LISTRIK TENAGA MIKRO HIDRO (PLTMH) BERKAPASITAS 4,88 kW DI KOTO ANAU KABUPATEN SOLOK," Abstr. dan Artik. Ilm. Prodi Tek. Mesin, vol. 5, no. 2, pp. 1-13, 2015.

[7] Ikrar Hanggara dan Harvi Irvani, "POTENSI PLTMH (PEMBANGKIT LISTRIK TENAGA MIKRO HIDRO) DI KECAMATAN NGANTANG KABUPATEN MALANG JAWA TIMUR,” J. Reka Buana, vol. 2, no. 2, pp. 149-155, 2017.

[8] F. R. dan R. A. C. Fachruddin, Adi Syuriadi, Ainun Nidhar, "PENGUJIAN VARIASI JUMLAH DAN SUDUT BILAH KINCIR AIR TIPE BREASTSHOT," POLITEKNOLOGI, vol. 14 , no. $3,2015$.

[9] G. Muller and C. Wolter, "The breastshot waterwheel: design and model tests," Eng. Sustain., vol. 57, no. S4, pp. 203-211, 2004. 